\title{
THE PLACE OF A GRAPHIC DESIGNER IN ENVIRONMENTAL SUSTAINABILITY
}

\author{
NDEM, EMMANUEL JOSEPH \\ Department of Fine and Industrial Arts \\ University of Uyo, Uyo
}

\begin{abstract}
Most graphic designers are not aware that solving problem through the process of design has adverse impact on the environment. How can this be made known to them is what this paper examines by highlighting the place of a graphic designer in environmental sustainability. This paper is aimed at creating awareness on the role of a graphic designer in environmental sustainability with the objective of educating designers on the need to providing environmental solutions using graphic design and also to encourage graphic designers to take sustainable design challenges. The method used in this research is documentary analysis. This was carried out by collecting data secondary sources. Finally, the paper suggests a strategy which leads to the involvement of community to promote the uptake of sustainability.
\end{abstract}

Keyword: Graphic, Designer, Environmental, Sustainability

\section{INTRODUCTION}

The growing concerns for the environment and climate change, together with issues of poverty, increasing difference between societies and the tensions brought about by social inequalities, have placed sustainable development under the spotlight. Industrial productions are some of the sources of all environmental problems. Major issues such as pollution, deforestation, species loss and global warming are all side-effects of the activities that provide consumers with endless consumer goods on the market today. National and international institutions, policy makers and cross-country initiatives as well as practitioners and academia, have increased the attention given to social and environmental sustainability worldwide. Graphic designers have a crucial role to play in achieving a more socially ordered and sustainable environment, since they must they must have to provide the solutions to some sets of environmental problems without increasing others.

Graphic designers are no longer seen solely as the producers of aesthetic "things," but are being valued for their problem-solving skills as well as the ability to help businesses and organizations strategize to appeal and engage customers through effective and persuasive graphic design. In addition, both designers and the clients they serve are increasingly expected to consider issues of sustainability by taking responsibility for the impact of the products and systems they create in the environment. However, graphic designers who lack formal training in sustainable design thinking and methodologies are unprepared to take on this sustainable design challenge, therefore, to prepare them to make this transition, emerging sustainable design roles and practices need to be identified and defined.

Thinking of designers as mere visual stylists is underestimating both their power and responsibility towards their audience, their message and creations within the sustained environment. Presently, the educational background of most graphic designers consisted mainly in aesthetical culture and computer programs' literacy. There exist a few different reasons for the lack of sustainable emphasis in graphic design: a lack of education simply keeps designers ignorant, the trendcentered discipline sees sustainable design as a less profitable route, and designers just cannot seem to integrate the guidelines of sustainability into an already-formed standards of design, this is because most graphic designers see sustainability and its application to design as noble, but unnecessary.

This paper is aimed at creating awareness on the role of the graphic designer in environmental sustainability with the 
objective of educating designers on the need to providing environmental friendly solutions using graphic design and also to encourage graphic designers to take on sustainable design challenges. It will further expose designers on the impact of their work to the environment.

\section{CONCEPTUAL FRAMEWORK}

Irwin Concept of Change: According to Irwin (2015), Creating sustainable Design is based on a different idea about change. Instead of thinking about cause-and-effect, top-downbased models of change, sustainable design is based on change as it develops within open, complex systems (Irwin, 2015). This kind of change can be guided and catalyzed, but never totally controlled and outcomes are hard to predict (Irwin, 2015). For example, instead of pushing people to drive less in order to slow climate change, change within a transitional framework would more likely create ways for people to drive less, see how that action effects climate change, and move forward from there. Its application in this paper is that instead of designers to encourage people to stop endangering environment, they should see the need to create products that when used will not endanger the environment.

\section{ENVIRONMENTAL SUSTAINABILITY}

Sustainability is the process of Striving to meet the needs of people, culture, and business as today in a way that restores the planet and does not compromise our ability to meet the needs of future generations.

In understanding environmental sustainability the World Commission on the Environment and Development which is also known as the Brundtland Commission, developed as definition that is very popular today which states that, “..Sustainable development is development that meets the needs of the present without compromising the ability of future generations to meet their own needs", (Blowers, A. et al, 2012).

Fuad-Luke (2009) identified that graphic designers have been at the fore-front in the campaign for change as at 1860 in a movement known as the suffragette movement (design-led activism), which involves graphic designers engaging in discussions about social problems. The suffragette movement attests that graphic designers have a central role to play in the activism's wider purpose. Sam (2010) observed that, even though Walt Kelly,
Robert Rauschenberg and The Washingtonian magazine created posters for the first Earth Day in 1970, their central roles in design-led activism via graphic design outlets were focused most directly on issues such as AIDS, equality, race, war, democracy and poverty, which clearly have direct links to sustainability as a system's theory approach, but were not connected as such during this time. (Sams, 2010).

As this shift in the field of design begins, it started by attaching itself to architecture, interior design and product design and then meanders over to the field of graphic design. Graphic design as a profession began the paradigm shift from promoting and educating the public about environmental sustainability into actually infusing it into practice, process and making it a core value of responsible design. Bierut and Friedman were of the view that most graphic designers become synonymous with the activist roles they played in World War II and during the first environmental movement of the 1970s (Bierut and Friedman, et al 2009). However, much of the progress on environmental sustainability during this time was facilitated by governance and initiatives from graphic designs organizations that find a critical need to keep pulse with their members, who during the wave of 1999-2005 were educating, speaking and designing about the importance of sustainability as a primal goal in the field and society at large. And, in the wake of silence or dedicated efforts potentially nonpublic at the time, many new 'design-related' NGOs and project-based organizations develop, but with the audience of the graphic designer, and the public.

\section{SUSTAINABLE GRAPHIC DESIGN}

Sustainable graphic design is the application of sustainability principles to the field of graphic design. A sustainable graphic designer would use strategies, processes, and materials that respect the four elements of sustainability: society, environment, economy, and culture. In actual application to communication projects, this may include looking at material life cycles and supply chains for environmental, social, and economic concerns; assessing the true needs of an intended audience through a human-centered design approach; translating design solutions into real economic value for stakeholders; and 
creating truthful and persuasive messaging that empowers others to take sustainable action. Sustainable graphic design should both walk and talk the values of sustainability.

According to Manzini and Vezzoli (2002), the concept of Design for Sustainability (DFS) is strongly related to the capacity of promoting production systems that can respond to some social and environmental requirements in their products using as less natural resources as possible, in comparison to the current patterns. In these terms, the designers and decision makers have to coordinate every product, service and communication that can contribute to clarify the design alternatives and technical solutions in order to attend social and cultural innovations. The method apart from considering the life cycle of matters and its impacts on human and natural systems, also assumes that new behavior patterns are taking place over the market in a point that consumers demand from producers much more conformity with environmentally sustainable, socially acceptable and culturally attractively ideas.

Benson, (2007) argues that graphic designers have ignored environmental issues in their work process and suggests solutions that might change this. He highlighted in his article a projection made by the UN report in 2007 that the population will increase by 2.6 billion over the next forty to fifty years, leading to increased demand on the world's natural resources to satisfy our daily and economic necessities such as the need for clean water, fresh air, safe food, jobs, housing and dependable transportation (Benson, 2007). According to him 'these new demands will unavoidably increase deforestation and its effects, and consequently add to the existing pollution of our air and water if we continue to follow our current design practices (Benson, 2007). As a solution Benson suggests that graphic designers shouldn't 'wait for others to act but instead to lead the sustainable design revolution'.

Benson, (2007) When describing what sustainability means for graphic design, looks at the tools graphic designers are using on a daily basis. These include paper and printing processes that involve and increase the use of natural resources. He summarizes that 'for the graphic designer to practice sustainably, all of the materials and energy utilized in every project must be renewable, recyclable and/or reusable.' (Benson, 2007).
However, these are not the only things that should be changed in order to achieve sustainability in graphic design. $\mathrm{He}$ suggests creating a unified measurements system that would measure the positive impact designers could make by using sustainable materials. Also, he spots other problems which designers face in preventing them from being sustainable, and this includes knowledge about sustainability itself. Benson states that it is imperative for the graphic designer to be educated about sustainability and to discuss project goals at length before embarking on any design endeavor. Educating oneself is just as important as educating one's client (Benson, 2007). He adds that sustainability should be taken into account at the start of the design process. According to him, designers should consider if there are alternative ways to produce the final solution. For instance making it digital or creating an event-based communication product. (Benson, 2007)

\section{GRAPHIC DESIGNER AND ENVIRONMENTAL ISSUES}

Designers are taking decisions and their decisions in various ways can or cannot support the environment. There are many environmental issues that are connected with the work of a graphic designer. Some of those are: Tropical deforestation, Waste, Resource consumption, The green house effect or global warming, The ozone layer, Water pollution etc

If we analyze each of these issues separately, we will realize the prospects that the work of the graphic designer has towards promoting sustainability. The following analysis concerning design decisions is given by MacKenzie, D. (1991).

- Tropical deforestation: The increase claim in Europe, North America and Japan for tropical hard woods is met by forestry applications which are not sustainable. Some companies claim that they re-plant and cut down only a small amount of trees, but the mass of felled timber results in loss of unique forests. Many species have been destroyed and many more are now in danger of disappearance. Tropical hard woods tend to be associated with high value end-uses, such as pieces of furniture, musical instruments and long-lasting boards for exterior protection of buildings. A great deal of them however, is used for chipboard, plywood and window frames. Also we are using those in other areas where other materials would be totally appropriate. The simple design decision is not to indicate any 
tropical woods; unless it can be proved that they are produced in a sustainable way. Timber merchants should be able to provide that information and all trustworthy merchants should at the present be capable to advise and supply good alternatives for traditional tropical hard woods.

- Waste: The most efficient way of addressing the waste disposal problem is to generate less waste. This is an area were designers will have a very important role to play and where good design can really make a difference. For example, when choosing materials and in particular, when launching new material, designers should take into consideration the impact of that material on the eventual disposal.

- Resource consumption By creating a fashion for minimalism is one approach, but another could be to design multi-purpose furniture and kitchen appliances which could be replaced by machines which perform different tasks.

- The Green House effect or global warming: Prospects exist for scientists and designers to design products and buildings powered by alternative sources of energy, but perhaps the single most important theme for design generally, is energy efficiency. The quantity of energy used to produce different materials varies widely. For example aluminum uses up huge quantities of energy, but can subsequently be recycled several times with low energy costs. Designers can play a significant role in conserving energy in different ways: a)By designing products that can be recycled. b)By indicating materials which have been produced efficiently. Many packaging manufacturers are now providing details of the energy costs of different materials. c)By using insulation materials, or solar panels together with construction techniques that harness the warmth of the earth. These can drastically lessen the energy requirements of buildings.

- The ozone layer: There are very few cases where CFCs (Choloflurocarbons) are needed, and the designers should make sure that they are specified. Alternatives exist for almost every use: insulation materials are being developed including one that uses waste paper. Refrigerator and air-conditioning now have an array of alternatives that have been tested.

- Water pollution: There are ways in which all designers can help to reduce water pollution and ease the storage of clean water. This will be as important in some regions as saving energy. Designers can try to design household appliances with far less water. Creative devises for collecting and using rain water also are also required. Further, the designer examines the record of providers of raw materials and components to ensure that their manufacturing processes are not polluting. As minimum requirements, providers should be able to demonstrate that have not broken local legislation concerning emissions.

\section{THE ROLE OF GRAPHIC DESIGNER IN ENVIRONMENTAL SUSTAINABILITY}

According to K. I. Kazamia and M. O. Kafaridou, (2010) 'The role of the designer in developing a sustainable society is not simply to create 'sustainable products' but rather to envision products, processes, and services that encourage widespread sustainable behavior'

Angharad Thomas (2006), opined that the designer should be seen as a value driven citizen of society who sees his/her experience and expertise as a catalyst for greater good. And can, as Thomas (2006) contends, play a role in alleviating poverty through their work, and their ability to connect with other designers who also feel the same pull-towards social change. The entire profession must be reinvented towards this model, if environmental sustainability will ever become more than an art nouveau, graffiti or ornamental-based design trend.

Nicola Morelli (2007) suggests that in order for design and industry to be successful in meeting social and environmental goals in the future, the relationship between client and designer changes, potentially and drastically. Morelli (2007) suggests that, "For these people [clients], designers will no longer be required to produce finite solutions but rather scenarios, platforms, and operative strategies to enable them to co-produce their own solutions." Although, this concept might feel strange (and designer's have a strong desire to be in control at all times), it provides for a much more cooperative and solutions-based approach to design, that is, more sustainable for the clients and their communities.

The idea that graphic designers should take into consideration the environment impact of their work is not new. The graphic designer was in a powerful position to help create a better world by considering environmental issues and creating environmental process and products. In addition to that, rising public concern is being 
translated into action in many countries. For example, people are demonstrating their feelings through their preferences, by changing their behaviour to accommodate recycling or energy efficiency, and by using environment criteria in their purchasing decisions as consumers.

Graphic designer and author of Sustainability in the Design Process, Peter Fine emphasizes packaging design as the most relevant means of permeating greener practices in consumer consciousness; he encourages designers to make packaging more functional-giving them the ability to stack upon one another, incorporating facets that serve as measuring instruments on the packaging, etc. This increases the value of a product, not monetarily but fundamentally. When a package is more versatile, a consumer is more likely to keep that product and reuse the packaging in ways that keep products out of landfills (Lehrer 2013). Packaging has a multi-faceted purpose in the sustainable design movement to relieve the consumer of some burden as well as encourage them to use more versatile products or be creative in their own daily lives.

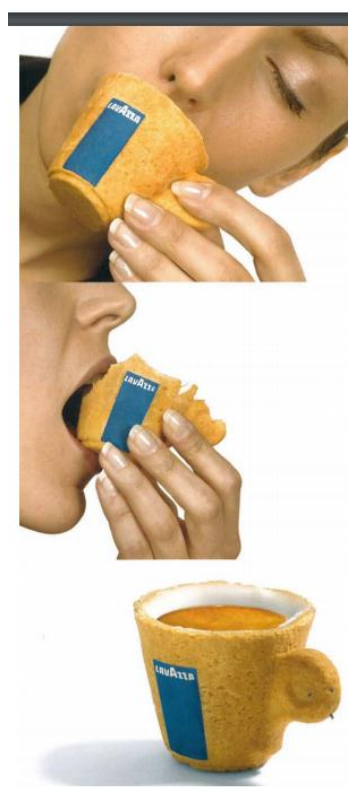

Lavazza's edible coffee cup is a two-in-one product which avoids waste in more than one way

Source: www.goodgraphicsdesign.com
Environmental problems become an increasingly important aspect of the designer's work to minimise the risks arising from the failure of a product or process. Because of the rapid technological development, environmental problems increase every day. On the other hand, new technologies often tend to be less polluting and dangerous than what they replace, and hence designers may find themselves in the forefront of identifying problems which must be addressed by technology. Sometimes, existing technologies may not be able to provide the solution, and the designer may have to influence the development of a new technological approach. Designers must also follow technological developments in order to be sure of incorporating the most environmentally advanced technologies.

Designers can make a significant difference to the effect of a product because they are responsible for influencing the key decisions. These determine the choice of material; how long the product will last; how effectively it uses energy; and how easily it may be reclaimed and re-used. The aims of environment-conscious designer are to use the minimum resources throughout, to get the maximum possible use and value out of the least quantity of materials and energy, and to minimize pollution created during the manufacture and life of the product.

Usual definitions of good design already include criteria such as successful performance, ease of use, safety, simplicity of maintenance, appropriate materials, efficiency of manufacture, attractive appearance and good for money. Designing for sustainable markets does not ignore the traditional criteria for good design, but it does demand that some are given different weightings and that new considerations are also taken into account. For example; the designer can no longer develop a product in isolation from the effects that the materials and production processes may have on the environment, or without thinking through the implications of eventual disposal.

\section{EDUCATING THE DESIGNER ON SUSTAINABLE PRACTICE: IT'S SIGNIFICANCE}

A graphic designer keen on adopting sustainable practices as a part of his work ethics needs to be educated on the environmental repercussions of the paper industry to be able to identify the issues and make informed sustainable choices. Currently, 


\section{International Journal of Engineering Applied Sciences and Technology, 2019 \\ Vol. 4, Issue 4, ISSN No. 2455-2143, Pages 251-257 \\ Published Online August 2019 in IJEAST (http://www.ijeast.com)}

it is a personal process to go through, as most graphic design schools curriculums do not cover the subject of sustainability, as aberrant as it may sound. A proper education in sustainable graphic design would greatly benefit the professional designers to-be in that they would be extensively aware of the environmental issues they will have to face, and of their remedies. If communication design schools could add sustainable design thinking to their curriculum, not only would it create that needed baseline for our industry, but it would also produce an army of young, motivated designers equipped with this new (and much needed) set of tools - ready to offer great value to any design firm / business. (gdusa.com, 2012).

A skillful designer with knowledge in sustainability will have more chance to be hired on complex and large printing projects. Sustainable graphic designers with a much broader knowledge, therefore skills, will increasingly be more valuable in a very competitive marketplace and the ones unwilling to change will consequently become irrelevant.

Through education, open dialogue and transparent relations to clients and audience, graphic designers need to learn the faculty to integrate sustainable practices as an elementary part of their work ethics and creative problem-solving abilities. It is also important that the shift to sustainable practices takes its roots from a personal conviction, to change the status quo and build a cleaner and more efficient alternative system. Due to the unique position that graphic designers occupy in the print production process - the centerpiece between businesses of all sorts and their audience - they have their part to play in the message they craft and therefore a certain power to influence the end user. It is obvious that the problems arising from environmental concerns are very complex and allencompassing. It questions our values and lifestyles, particularly our unbridled consuming habits. In his book The Green Marketing Manifesto, John Grant (2007, 10) precisely sums up our ambition for probably decades to come: - Instead of focusing on the problems-which can seem hopeless at times-we need to see the opportunity in creating alternatives. We need to overcome any obstacles and focus on solutions and actions that will benefit the whole humankind.

\section{CONCLUSION}

This paper analyzes some concepts such as Design for Environment and Design for Sustainability associated to the work of designers within the sustainable development context. The idea is to better understand the ways, in which designers should act in order to achieve sustainability in different views, such as environment, society, ethics, culture, economy, etc.

\section{REFERENCES}

1. Blowers, A. et al, (2012). Is sustainable development sustainable? Journal of Integrative Environmental Sciences. 1(9): 1

2. Bierut, M. et al (2010). Green Patriot Posters, Los Angeles: Metropolis Books.

3. Benson, E. (2007) What is sustainable graphic design? Available at: http://designphilosophypolitics.inform atics.indiana.edu/?p=48

Retrieved15-2-2018

4. Dritz, A. (2014). Closing the Sustainability Gap:The Emerging Role of Sustainable Graphic Designer. MA Thesis Unpublished. Minneapolis College of Art and Design

5. Fuad-Luke, A. (2009) Design Activism: Beautiful Strangeness for a Sustainable World, London: Earthscan

6. Irwin, T. (2015). Transition Design: A Proposal for a New Area of Design Practice, Study, and Research. Design and Culture, 7(2), 229-246.

7. Kazamia, I.V. and Kafaridou, ,.O (2010) How a designer can support Sustanability in a Sreative Way. International design conference design. Croatia:Dubrovnik,

8. Lehrer, J. (2013). "Reusable Transport Packaging: Good for the Planet, Operational Efficiency and Brand Protection." Sustainable Brands

9. Mackenzie D. (1991), "Green Design, Design for the Environment", Laurence King Ltd.,

10. Morelli, N. (2007) 'Social Innovation and New Industrial Contexts: Can Designers "Industrialize" Socially Responsible Solutions?' Design Issues, 
International Journal of Engineering Applied Sciences and Technology, 2019

Vol. 4, Issue 4, ISSN No. 2455-2143, Pages 251-257

Published Online August 2019 in IJEAST (http://www.ijeast.com)

23(4): 3-21.

11. Sams, C. (2010) 'Earth Day Posters: 40 Years of Art Inspiring Change' Take Part available at http://www.takepart.com/article/2010/ 04/21/earth-day-posters-40-years-artinspiring-change.

12. Thomas, A. (2006) 'Design, Poverty, and Sustainable Development' Design Issues, 22(4): 54-65. 